\title{
Predictors of Lipid Profile Abnormalities Among Patients with Metabolic Syndrome in Southwest Ethiopia: A Cross-Sectional Study
}

\author{
Kassahun Haile $\mathbb{D}^{\prime}$ \\ Admasu Haile' \\ Abebe Timerga ${ }^{2}$ \\ 'Department of Medical Laboratory \\ Science, College of Medicine and Health \\ Sciences, Wolkite University, Wolkite, \\ Ethiopia; ${ }^{2}$ Department of Biomedical \\ Science, College of Medicine and Health \\ Sciences, Wolkite University, Wolkite, \\ Ethiopia
}

Background: Lipid profile abnormalities are an integral part of metabolic syndrome (MetS) and major underlying causes of cardiovascular disease (CVD) and type-2 diabetes mellitus (T2DM). Lipid profile abnormalities in a patient with MetS are resulted due to the presence of central obesity and insulin resistance. In Ethiopia, the burden and predictors of lipid profile abnormalities in a patient with MetS are not well known. Thus, this study aimed to determine the prevalence of lipid profile abnormalities and predictors among patients with MetS in southwest Ethiopia.

Methods and Materials: A cross-sectional study was conducted among 381 patients with MetS from September to December 2019 with a response rate of 100\%. A structured questionnaire was used to collect data on socio-demographic and behavioral factors. Waist circumference, height, weight, and blood pressures were measured. The venous blood sample was collected for glucose and lipid profile determination. Data were entered and analyzed by using SPSS version 21. Binary logistic regression and Pearson's correlation analyses were performed. A p-value was set at a $<0.05$ for statistical significance.

Results: In this study, about $58 \%$ of participants were at least one or more lipid profile abnormalities with the $95 \%$ CI (52.8-62.7). About $67.2 \%, 44.6 \%, 18.4 \%$, and $14.2 \%$ of study participants were low HDL, high TG, LDL, and TC, respectively. Central obesity (adjusted odds ratio (AOR): 1.89, 95\% CI: 1.14-3.14), increasing age (AOR: 2.08, 95\% CI: 1.27-3.4), higher BMI (AOR: 2.06, 95\% CI: 1.23-3.4), being hypertensive (AOR: 3.48, 95\% CI: 2.125.7) and increasing blood glucose level (AOR: 2.34, 95\% CI: 1.36-4.03) were independent predictors of lipid profile abnormalities (dyslipidemia).

Conclusion: In this study area, a high (58\%) prevalence of dyslipidemia was observed in study participants, and increasing age, higher BMI, central obesity, hypertension, and high blood glucose level were identified as independent predictors of dyslipidemia among patients with MetS. Prevention and control of dyslipidemia and its predictors among patients with MetS were recommended.

Keywords: metabolic syndrome, lipid profile abnormalities, Ethiopia

\section{Introduction}

Metabolic syndromes are a growing major public health concern worldwide, and it affects both developed and developing countries. ${ }^{1}$ A study reported $37.05 \%, 34.1 \%$, $69.1 \%$, and $21.6 \%$ prevalence of MetS in Iran, ${ }^{2}$ Brazil $^{3}{ }^{3}$ Ghana, ${ }^{4}$ and Indonesia, ${ }^{5}$ respectively. Whereas a large number of the population were affected in different parts of Ethiopia, the proportion varies from $20.3 \%$ to $55.1 \%$ across the country. ${ }^{6-8}$
Correspondence: Kassahun Haile Department of Medical Laboratory Science, College of Medicine and Health Sciences, Wolkite University, P.O. Box: 07 Wolkite, Ethiopia

Tel +25 I 926-07-43-74

Fax +25 I II 322004 I

Email kassahaile07@gmail.com 
A sedentary way of life, increase in urbanization, surplus energy intake, and increasing burden of obesity were factors that contribute to the increasing global burden of MetS. ${ }^{9}$

Metabolic syndrome consists of different abnormalities that include raised blood pressure, lipid profile abnormalities (elevated triglycerides (TG) and low high-density lipoprotein cholesterol (LDL)), raised fasting blood glucose, and central obesity. ${ }^{10}$ The major underlying pathophysiology for the development of MetS is mainly based on insulin resistance and central obesity. ${ }^{11}$ The continuous increase in the global burden of MetS leads to serious public health concerns; it increases the risk of CVD and T2DM and also contributes to CVD-related morbidity and mortality. ${ }^{12}$

Dyslipidemia is an integral part of MetS and the major underlying causes of CVD and T2DM in a patient with MetS. ${ }^{13-16}$ Dyslipidemia associated with the MetS was elevated triglycerides, low high-density lipoprotein (HDL), and high LDL. ${ }^{17-19}$ The presence of insulin resistance and central obesity in individuals with MetS have been associated with a cluster of lipid profile abnormalities. $^{20,21}$ Insulin resistance and compensatory hyperinsulinemia in individuals with MetS lead to the overproduction of LDL particles. ${ }^{11,21}$ A relative deficiency of lipoprotein lipase resulted in a decreased clearance of fasting and postprandial triglyceride-rich lipoproteins (TRLs) and the decreased production of HDL particles. ${ }^{22}$ The resulting increased concentration of cholesteryl esterrich fasting and postprandial TRLs is the central lipid profile abnormality of the MetS. ${ }^{21}$ Resistance to insulin action or insulin deprivation is associated with increased lipolysis, intra-abdominal fat, which is metabolically very active, releases free fatty acid into the portal circulation, and the liver converts free fatty acid into triglycerides; this may probably result in hypertriglyceridemia. ${ }^{20}$ Hypertriglyceridemia is one of the most common MetS components and is an important consideration in the formulation of cardiovascular preventive programs because elevated triglycerides confer an increased risk of CVD. ${ }^{13,20}$ Also, elevated levels of LDL are a major risk factor for CVD, and its reduction is the primary target of pharmacotherapy. ${ }^{20,21}$

Determining the prevalence of dyslipidemia in a patient with MetS is vital to promote a patient's health care and to prevent CVD-related morbidity and mortality. In Ethiopia, different studies reported a high prevalence of
MetS, ${ }^{6,8}$ however, the burden and predictors of dyslipidemia in a patient with MetS are not well known.

Determination of the prevalence and its predictors of lipid profile abnormalities is important for the management of the patient with MetS and formulation of cardiovascular preventive measures to reduce its risk and complication. Therefore, this study aimed to determine the prevalence and predictors of dyslipidemia and to assess the relationships of lipid profile with fasting blood glucose, blood pressure, and anthropometric indices in patients with MetS in Ethiopia.

\section{Method and Materials Study Area}

The study was conducted in Jimma Medical Center, which is located $352 \mathrm{~km}$ far from Addis Ababa, the capital city of Ethiopia. Jimma Medical Center provides teaching, diagnostic, and referral service in the southwestern part of the country, and its catechumen's area population is around 15 million inhabitants. The study was conducted among patients admitted with MetS in Jimma Medical Ward.

\section{Study Design and Period}

A cross-sectional study was conducted from September to December 2019.

\section{Sample Size and Sampling Technique}

A single population proportion formula was used to determine sample size by considering the following assumption; a $95 \%$ confidence interval (CI), a $5 \%$ margin of error, and a $45.1 \%$ magnitude of high serum $\mathrm{TG}$ value in a patient with MetS. ${ }^{8}$ The final sample size of the study was 381. All identified MetS patients (age $\geq 18$ years) who had been admitted to Jimma Medical Ward were conclusively included in the study until attaining sample size.

\section{Inclusion Criteria}

Study participants with waist circumference $(\geq 102 \mathrm{~cm}$ for men and $\geq 88 \mathrm{~cm}$ for women), raised triglyceride level $\geq 150 \mathrm{mg} / \mathrm{dl}$, reduced HDL $(<40 \mathrm{mg} / \mathrm{dl}$ in men, $<50 \mathrm{mg}$ / $\mathrm{dl}$ in women), raised blood pressure (systolic blood pressure (SBP) $\geq 130$ or diastolic blood pressure (DBP) $\geq 85 \mathrm{~mm} \mathrm{Hg}$ ) and raised fasting plasma glucose $\geq 110 \mathrm{mg}$ / dl, who fulfills Adult Treatment Panel III criteria for MetS, were included in the study. ${ }^{23}$ 


\section{Exclusion Criteria}

Study participants who had a pregnancy, malignancy, known history of chronic liver, cardiac problems, renal diseases, and severely ill patients were excluded from the study.

\section{Data Collection Methods and Techniques}

A structured questionnaire was used to collect data on socio-demographic, economic, and behavioural characteristics.

\section{Physical Examination}

Anthropometric measurements were administered by trained professional nurses by using a standardized protocol. Waist circumference was measured at the midpoint between the lower margin of the least palpable rib and the top of the hip or minimal waist using stretch-resistant tape; then, central obesity was defined as waist circumference $\geq 102 \mathrm{~cm}$ for men and $\geq 88 \mathrm{~cm}$ for women. Height and weight were measured from all study participants based on World health organization (WHO) guideline, and body mass index (BMI) was determined as weight in kilogram divided by the square of height in meter and categorized as overweight $\left(\mathrm{BMI}=25-29.9 \mathrm{~kg} / \mathrm{m}^{2}\right)$, and obese (BMI $\geq 30 \mathrm{~kg} / \mathrm{m}^{2}$ ). Blood pressure was measured digitally by using Micro life BP (Micro life BP A50, Switzerland) from the right upper arm. Hypertension in patients with metabolic syndrome was defined as systolic blood pressure (SBP; $\geq 130$ millimeters of mercury $[\mathrm{mmHg}]$ ) or diastolic blood pressure (DBP; $\geq 85 \mathrm{mmHg}$ ).

\section{Blood Specimen Collection and Analysis}

Four milliliters of the blood sample were collected from each participant for serum glucose and lipid profile analysis. After the drawn sample stayed for 30 minutes at room temperature, serum was separated from the collected blood sample by using Rotanta 960 centrifuge (at $4000 \mathrm{rpm}$ for 5 minutes). The serum lipid parameters (TG, LDL, HDL, and total cholesterol (TC)) and glucose were measured by ABX Pentra chemistry analyzer (Horiba ABX, France) following the manufacturer's instructions and standard operating procedures of the hospitals. Lipid profile abnormalities (dyslipidemia) in patients with MetS were defined as the presence of at least one or more lipid profile abnormalities from the following; $\mathrm{TG} \geq 150$ milligram per deciliter (mg/dl), HDL $\leq 40 \mathrm{mg} / \mathrm{dl}$ in men, and $\leq 50 \mathrm{mg} / \mathrm{dl}$ in women, $\mathrm{TC} \geq 200$ ( $\mathrm{mg} / \mathrm{dl})$, or LDL $(\geq 100 \mathrm{mg} / \mathrm{dl})$.

\section{Operational Definition}

Metabolic syndrome was defined according to the Adult Treatment Panel III criteria definition, as the presence of any three of the following: waist circumference $\geq 102 \mathrm{~cm}$ in men or $\geq 88 \mathrm{~cm}$ in women; blood pressure $\geq 130 / \geq 85 \mathrm{~mm}$ $\mathrm{Hg}$; fasting blood glucose $\geq 100 \mathrm{mg} / \mathrm{dl} ; \mathrm{TG} \geq 150 \mathrm{mg} / \mathrm{dl}$ and low HDL-C $<40 \mathrm{mg} / \mathrm{dl}$ in men or $<50 \mathrm{mg} / \mathrm{dl}$ in women. ${ }^{23}$

Alcohol consumption: study participants who consume more than 3-4 units for men and more than 2-3 units for women daily during the time of the data collection. ${ }^{24}$

Smoking cigarette: study participants who had the habit of smoking one or more manufactured or handrolled tobacco during the study period. Physical activity: study participants who were involved in moderate physical activities such as walking, cycling, or doing that had significant benefits for health with expending energy. ${ }^{25}$

Fruit and vegetable consumption: study participants who had the habit of consumption of fruit and vegetables at least once per day during the time of the data collection. $^{26}$

\section{Data Analysis and Interpretation}

Data were entered and analyzed by using SPSS version 21 (SPSS, Chicago, IL, USA). Data were described as frequency, percentage, mean, and standard deviation tables. Binary logistic regression analyses (bivariate and multivariable) were performed to identify independent predictors of dyslipidemia. Crude (COR) and adjusted odds ratio (AOR) with their respective $95 \%$ CI were calculated. The candidate predictors for multivariate analysis were identified in bivariate analysis by considering p-value $<0.25$. $^{6}$ Multivariable analysis was used to control confounding variables and identify independent predictors for the prevalence of dyslipidemia. Variables in a multivariate analysis with a p-value $<0.05$ were taken as significantly associated predictors with dyslipidemia. Pearson's correlation was used to see relationships between lipid profile and other components of MetS. P-value $<0.05$ was considered statistically significant.

\section{Results}

A total of 381 patients with MetS were included in this study, with a response rate of $100 \%$; about $58 \%(n=221)$ were females. The mean $( \pm \mathrm{SD})$ ages of the study participants were $50.2 \pm 14.4$ years, which range from 18 to 79 years. About $68 \%$ (259), $40.2 \%$ (153), $73.8 \%$ (281) of study participants had central obesity, hypertension, and fasting blood 
Table I Socio-Demographic, Behavioural, and Other Related Characteristics of a Patient with Metabolic Syndrome in Southwest Ethiopia from September to December 2019

\begin{tabular}{|c|c|c|}
\hline Characteristics & Categories & n (\%) \\
\hline \multirow[t]{2}{*}{ Residence } & Urban & $\begin{array}{l}210 \\
(55.1 \%)\end{array}$ \\
\hline & Rural & $|7|(44.9)$ \\
\hline \multirow[t]{2}{*}{ Age in years } & $<50$ & 183(48) \\
\hline & $\geq 50$ & $198(52)$ \\
\hline \multirow[t]{2}{*}{ Sex } & Female & $22 I(58)$ \\
\hline & Male & $160(42)$ \\
\hline \multirow[t]{2}{*}{ Marital status } & Single & $87(22.8)$ \\
\hline & Married & $294(77.2)$ \\
\hline \multirow[t]{4}{*}{ Educational level } & Illiterate & $214(56.2)$ \\
\hline & Primary & $55(14.4)$ \\
\hline & Secondary & $73(19.2)$ \\
\hline & Collage/University & $39(10.2)$ \\
\hline \multirow[t]{2}{*}{ Monthly income in ETB* } & $<1500$ & $120(31.5)$ \\
\hline & $\geq 1500$ & $26 I(68.5)$ \\
\hline \multirow[t]{5}{*}{ Occupation } & Farmer & $73(19.2)$ \\
\hline & Merchant & 183(48) \\
\hline & $\begin{array}{l}\text { Government } \\
\text { employee }\end{array}$ & $98(25.7)$ \\
\hline & Daily laborer & $16(4.2)$ \\
\hline & Students & $\mathrm{II}(2.9)$ \\
\hline \multirow[t]{2}{*}{ Drug intake } & No & $52(13.6)$ \\
\hline & Yes & $329(86.4)$ \\
\hline \multirow[t]{2}{*}{ Overweight } & No & $208(54.6)$ \\
\hline & Yes & $173(45.4)$ \\
\hline \multirow[t]{2}{*}{ Obese } & No & $262(68.8)$ \\
\hline & Yes & $119(31.2)$ \\
\hline \multirow[t]{2}{*}{ Central obesity } & No & $122(32)$ \\
\hline & Yes & $259(68)$ \\
\hline \multirow[t]{2}{*}{ Hypertension } & No & $228(59.8)$ \\
\hline & Yes & $153(40.2)$ \\
\hline \multirow[t]{2}{*}{ Fasting blood sugar } & $<110 \mathrm{mg} / \mathrm{dl}$ & $100(26.2)$ \\
\hline & $\geq 110 \mathrm{mg} / \mathrm{dl}$ & $28 I(73.8)$ \\
\hline
\end{tabular}

(Continued)
Table I (Continued).

\begin{tabular}{|l|l|l|}
\hline Characteristics & Categories & $\mathbf{n}(\%)$ \\
\hline \multirow{2}{*}{ Smoking cigarette } & No & $323(84.8)$ \\
\cline { 2 - 3 } & Yes & $58(15.2)$ \\
\hline \multirow{2}{*}{ Alcohol consumption } & No & $305(79.3)$ \\
\cline { 2 - 3 } & Yes & $79(20.7)$ \\
\hline \multirow{2}{*}{$\begin{array}{l}\text { vegetable } \\
\text { Physical activities }\end{array}$} & No & $17(4.5)$ \\
\cline { 2 - 3 } & Yes & $364(95.5)$ \\
\hline & No & $246(64.6)$ \\
\cline { 2 - 3 } & Yes & $135(35.5)$ \\
\hline
\end{tabular}

Abbreviations: *ETB, Ethiopian birr; $\mathrm{mg} / \mathrm{dl}$, milligram per decilitre.

glucose $\geq 110 \mathrm{mg} / \mathrm{dl}$, respectively. The mean $( \pm \mathrm{SD})$ of BMI, waist circumference, SBP, DBP, and fasting blood glucose was $26.8 \pm 4.19 \mathrm{~kg} / \mathrm{m}^{2}, 99.2 \pm 8.5 \mathrm{~cm}, 138.7 \pm 18.6 \mathrm{mmHg}, 88.8 \pm$ $9.7 \mathrm{mmHg}$, and $153.04 \pm 60.34 \mathrm{mg} / \mathrm{dl}$, respectively (Table 1).

\section{The Prevalence of Dyslipidemia Among Patients with Metabolic Syndrome}

The overall prevalence of dyslipidemia among patients with MetS was 58\% (221) with 95\% CI (52.8-62.7). The mean $( \pm \mathrm{SD})$ of TG, HDL, LDL, and TC was 147.2 $\pm 39.6 \mathrm{mg} / \mathrm{dl}, \quad 47.8 \pm 11.2 \mathrm{mg} / \mathrm{dl}, \quad 85.8 \pm 21.5 \mathrm{mg} / \mathrm{dl}$, and $148.4 \pm 44.6 \mathrm{mg} / \mathrm{dl}$, respectively. High proportions of dyslipidemia were found in urban dwellers $61 \%$ (128) and the age group $\geq 50$ years $66.2 \%$ (131). The percentages of dyslipidemia were $68.4 \%$ (54), 68.1\% (81), 64.5\% (167), $72.5 \%$ (111), and 62.6\% (176) in alcohol consumers, higher BMI, having central obesity, hypertensive and fasting blood glucose level $\geq 110 \mathrm{mg} / \mathrm{dl}$, respectively (Table 2). Individual lipid profile abnormality of high TG, low HDL, high LDL, and TC were identified in 44.6\% (170), 67.2\% (256), $18.4 \%$ (70), and $14.2 \%$ (54) of study participants, respectively.

\section{Correlation Analysis}

Correlation analyses of lipid profile with other MetS components were performed. Accordingly, serum level of TG showed statistically positive correlation with central obesity $(\mathrm{r}=0.21, \mathrm{p}=<0.001)$, fasting blood glucose $(\mathrm{r}=0.27$, $\mathrm{p}=<0.001)$, and hypertension $(\mathrm{r}=0.24, \mathrm{p}=<0.001)$. Serum concentration of HDL showed statistically positive correlation with overweight $(\mathrm{r}=0.1, \mathrm{p}=0.04)$ (Table 3$)$. 
Table 2 Multivariate Analysis of Predictors with Dyslipidemia Among Patients with Metabolic Syndrome in Southwest Ethiopia from September to December 2019

\begin{tabular}{|c|c|c|c|c|c|}
\hline \multirow[t]{2}{*}{ Predictors } & \multirow[t]{2}{*}{ Categories } & \multicolumn{2}{|c|}{ Dyslipidaemia } & \multirow[t]{2}{*}{$\operatorname{AOR}(95 \% \mathrm{Cl})$} & \multirow[t]{2}{*}{ P-value } \\
\hline & & No & Yes & & \\
\hline \multirow[t]{2}{*}{ Residence } & Urban & $82(39)$ & $128(61)$ & $1.16(0.7-1.93)$ & 0.54 \\
\hline & Rural & $78(45.6)$ & $93(54.4)$ & I & \\
\hline \multirow[t]{2}{*}{ Age in years } & $<50$ & $93(50.8)$ & $90(49.2)$ & I & \\
\hline & $\geq 50$ & $67(33.8)$ & $|3|(66.2)$ & $2.08(1.27-3.4)$ & $0.004 * *$ \\
\hline \multirow[t]{2}{*}{ Marital status } & Single & $43(49.4)$ & $44(50.6)$ & I & \\
\hline & Married & $117(39.8)$ & $177(60.2)$ & $0.92(0.5-1.6)$ & 0.79 \\
\hline \multirow[t]{4}{*}{ Educational level } & Illiterate & $85(39.7)$ & $129(60.3)$ & $1.92(0.85-4.3)$ & 0.11 \\
\hline & Primary & $24(43.6)$ & $3 I(56.4)$ & I.73(0.68-4.4) & 0.24 \\
\hline & Secondary & $30(4 I .1)$ & $43(58.9)$ & $1.9(0.78-4.6)$ & 0.15 \\
\hline & Collage/University & $21(53.8)$ & $18(46.2)$ & I & \\
\hline \multirow[t]{2}{*}{ Monthly income } & $<1500$ & $56(46.7)$ & $64(53.3)$ & I & \\
\hline & $\geq 1500$ & 104(39.8) & $157(60.2)$ & $1.35(0.8-2.2)$ & 0.23 \\
\hline \multirow[t]{2}{*}{ Obese } & No & $122(46.6)$ & $140(53.4)$ & I & \\
\hline & Yes & $38(31.9)$ & $8 I(68.1)$ & $2.06(1.23-3.4)$ & $0.006 * *$ \\
\hline \multirow[t]{2}{*}{ Central obesity } & No & $68(55.7)$ & $54(44.3)$ & I & \\
\hline & Yes & $92(35.5)$ & $167(64.5)$ & $1.89(1.14-3.14)$ & $0.013^{* *}$ \\
\hline \multirow[t]{2}{*}{ Hypertension } & No & $118(51.8)$ & $110(48.2)$ & I & \\
\hline & Yes & $42(27.5)$ & || $\mid(72.5)$ & $3.48(2.12-5.7)$ & $<0.001^{* *}$ \\
\hline \multirow[t]{2}{*}{ Fasting blood sugar } & $<110 \mathrm{mg} / \mathrm{dl}$ & $55(55)$ & $45(45)$ & 1 & \\
\hline & $\geq 110 \mathrm{mg} / \mathrm{dl}$ & $105(37.4)$ & $176(62.6)$ & $2.34(1.36-4.03)$ & $0.002 * *$ \\
\hline \multirow[t]{2}{*}{ Smoking cigarette } & No & $140(43.3)$ & $183(56.7)$ & I & \\
\hline & Yes & $20(34.5)$ & $38(65.5)$ & I.4(0.7-2.7) & 0.33 \\
\hline \multirow{2}{*}{$\begin{array}{l}\text { Alcohol } \\
\text { consumption }\end{array}$} & No & $135(44.7)$ & $167(55.3)$ & 1 & \\
\hline & Yes & $25(31.6)$ & $54(68.4)$ & I.5(0.85-2.8) & 0.15 \\
\hline
\end{tabular}

Notes: **Significantly associated predictors with dyslipidemia with $\mathrm{p}$ value $<0.05, \mathrm{I}$; reference category.

Abbreviations: AOR, adjusted odds ratio; $\mathrm{Cl}$, confidence interval; $\mathrm{mg} / \mathrm{dl}$, milligram per decilitre.

\section{Independent Predictors of Dyslipidemia}

In the bivariate analysis: being urban dweller, increasing age, being married, illiteracy, secondary in educational status, higher monthly income, smoking, alcohol consumption, being obese, having central obesity, hypertension, and high fasting blood glucose levels were identified as candidate predictors for multivariate analysis by considering p-value $<0.25$.
A significantly high prevalence of dyslipidemia was observed in older study participants (66.2\%) as compared to younger participants (AOR: 2.08, 95\% CI: 1.27-3.4, $\mathrm{p}=0.004)$. Obese MetS patients were 2 times higher odds of dyslipidemia compared to normal patients. The MetS patients having central obesity were nearly 2 times more likely to develop dyslipidemia (AOR: $1.89,95 \%$ CI: 1.14 3.14) compared to normal counterparts. A higher 
Table 3 Correlation Analysis of Lipid Profile with Fasting Blood Glucose, Hypertension, and Anthropometric Indices in Patients with Metabolic Syndrome

\begin{tabular}{|l|l|l|l|l|l|l|l|l|}
\hline Metabolic Syndrome Component & \multicolumn{2}{l}{ TG } & \multicolumn{2}{l|}{ HDL } & \multicolumn{2}{l|}{ LDL } & \multicolumn{2}{l|}{ TC } \\
\cline { 2 - 9 } & $\mathbf{r}$ & $\mathbf{p}$ & $\mathbf{r}$ & $\mathbf{p}$ & $\mathbf{r}$ & $\mathbf{p}$ & $\mathbf{r}$ & $\mathbf{p}$ \\
\hline Fasting blood glucose & 0.27 & $<0.001$ & -0.05 & 0.28 & 0.15 & 0.003 & 0.16 & 0.001 \\
Hypertension & 0.24 & $<0.001$ & -0.04 & 0.4 & 0.22 & $<0.001$ & 0.23 & $<0.001$ \\
Central obesity & 0.21 & $<0.001$ & -0.04 & 0.35 & 0.08 & 0.08 & 0.18 & $<0.001$ \\
Overweight & 0.007 & 0.89 & 0.1 & 0.04 & -0.02 & 0.66 & 0.006 & 0.9 \\
Obesity & 0.12 & 0.019 & -0.09 & 0.07 & 0.11 & 0.02 & 0.18 & $<0.001$ \\
\hline
\end{tabular}

Abbreviations: r, Pearson correlation coefficients; p, p-value for the correlation; TG, triglycerides; HDL, high-density lipoprotein cholesterol; LDL, low-density lipoprotein cholesterol; TC, total cholesterol.

proportion of dyslipidemia (72.5\%) was found in a MetS patient with hypertension than a non-hypertensive one, which was significant (AOR: 3.48, 95\% CI: 2.12-5.7). The study participants with higher blood glucose values were 2 times more likely to develop dyslipidemia than their normal counterparts (AOR: 2.34, 95\% CI: $1.36-$ 4.03) (Table 2).

\section{Discussion}

Individuals with MetS exhibit a characteristic pattern of serum lipid profile abnormalities. Identification of predictors of dyslipidemia among patients with MetS was important to employ effective risk factor modification and to hasten CVD-related morbidity and mortality. Thus, this study aimed to determine the prevalence and predictors of dyslipidemia and to assess its relationship with anthropometric indices, hypertension, and fasting blood glucose among patients with MetS in southwest Ethiopia.

In the current study, $58 \%$ of patients with MetS had at least one or more lipid profile abnormalities (dyslipidemia). This observation was consistent with studies conducted in Ethiopia. ${ }^{27,28}$ On the contrary, a higher burden of dyslipidemia was reported from Kenya $86.1 \%,{ }^{29}$ Nigeria $69.3 \%,{ }^{30}$ and Iran $75.3 \%{ }^{31}$ However, a lower burden of dyslipidemia was observed in China 49.06\%. ${ }^{32}$ Those observed differences might be due to variations in lifestyle and genetic disposition of the study participants.

Among patients having MetS; 44.6\%, 67.2\%, 18.4\%, and $14.2 \%$ of study participants had high TG, low HDL, high LDL, and high TC, respectively. The serum concentration of TG showed a statistically positive correlation with central obesity, hypertension, higher BMI, and fasting blood glucose. Besides, HDL showed a statistically positive correlation with overweight.
The present study found that $44.6 \% \%$ of the study participants had high serum TG concentrations. An increase in serum TG level in a MetS patient might be due to resistance to insulin action or insulin deprivation, which was associated with increased lipolysis, intraabdominal fat, which is metabolically very active, releases free fatty acid (FFA) into the portal circulation and the liver converts FFA into triglycerides, which result in high serum TG level. ${ }^{21,22}$ This finding was in line with studies reported in India, ${ }^{33}$ Iran $^{31}$ Brazil $^{34}{ }^{34}$ Malaysia, ${ }^{35}$ and Central America; ${ }^{36}$ however, this finding is lower than a study reported from Gondar, Ethiopia 56.6\%, ${ }^{37}$ Hawassa, Ethiopia $68.1 \%,{ }^{38}$ and Brazil $57.9 \%,{ }^{39}$ but higher than a report from Iran. ${ }^{31}$ The discrepancy in the burden of dyslipidemia might be due to differing cut points in some studies and dietary differences of the study participants.

High levels of TG and low levels of HDL in patients with MetS result from decreased clearance of these lipoproteins from the circulation. Hepatic lipoprotein lipase (LPL) is a major enzyme responsible for clearing TGcontaining lipoproteins from the circulation, and the presence of insulin resistance in a patient with MetS is associated with impaired LPL activity, which causes HDL levels to decline. ${ }^{20,22}$ The low HDL level was the most frequent lipid profile abnormality (67.2\%) found in this study, which was comparable with the study finding from Indonesia, ${ }^{18}$ the Philippines, ${ }^{40}$ Amazon, Brazil, ${ }^{3}$ and Nepal. ${ }^{41}$ Our finding was higher than the study findings reported from Tigray, Ethiopia 34.4\%, ${ }^{8}$ Addis Ababa, Ethiopia $48.6 \%,{ }^{6}$ India $19.4 \%,{ }^{33}$ and Central America $48.1 \%{ }^{36}$ This might be attributed due to an increase in urbanization, obesity, and reduced physical activity.

The elevated levels of LDL are a major risk factor for CVD, and its reduction is the primary target of 
pharmacotherapy. ${ }^{20,21}$ In the current study, $18.4 \%$ of the MetS patients had a high LDL level. This observation was in agreement with the finding reported from Ethiopia, ${ }^{42}$ the Philippines, ${ }^{40}$ and Iran, ${ }^{31}$ whereas our finding was much lower than the studies finding reported from Nepal $64.4 \%,{ }^{41}$ and Ethiopia $43.8 \%,{ }^{27}$ but higher than the report from India $9.7 \% .{ }^{33}$ Our study finding revealed a lower prevalence of elevated total cholesterol (14.2\%) compared to studies conducted in Brazil 54.8\%, ${ }^{34}$ and the Philippines $41 \%,{ }^{40}$ but it was consistent with a study reported from Jiangxi province, China $15.68 \%,{ }^{32}$ Chongqing, China $14.7 \%,{ }^{43}$ India $13.8 \%,{ }^{33}$ and Addis Ababa, Ethiopia $11.8 \%{ }^{44}$

In the present study, serum concentration of $\mathrm{TG}$ showed a statistically positive correlation with central obesity, fasting blood glucose, and hypertension. In addition, the serum concentration of HDL showed a statistically positive correlation with overweight. This observation was in agreement with a study conducted in Ethiopia, ${ }^{45}$ Brazil,${ }^{34}$ and Nepal. ${ }^{46}$

After adjusting for confounders, we found that increasing age, higher BMI, central obesity, high blood glucose value, and hypertension were independent predictors of dyslipidemia among MetS patients. Therefore, cardiovascular preventive measures to reduce its risk and complication should be used to prevent and control dyslipidemia among patients with MetS. A significantly high burden of dyslipidemia (66.2\%) was observed in older study participants, and older age was an independent predictor of dyslipidemia. This finding is in line with studies done in Ethiopia, ${ }^{27}$ and China. ${ }^{32,43}$

In our study, obesity was significantly associated with dyslipidemia. Obese MetS patients had 2 times higher odds of dyslipidemia compared to normal patients. This finding was in agreement with the study reported in China $^{32,43}$ and Kenya. ${ }^{29}$

The current study revealed that there is a statistically significant association between dyslipidemia and central obesity. The MetS patients having central obesity were nearly 2 times more likely to develop dyslipidemia compared to their normal counterparts. A similar finding was reported from China $^{43}$ and Thailand. ${ }^{47}$

A higher proportion of dyslipidemia (72.5\%) was found in a MetS patient with hypertension than a nonhypertensive one in this study. The burden of dyslipidemia was significantly associated with hypertension. This finding was in agreement with studies reported from Ethiopia, ${ }^{27,28}$ and Nepal. ${ }^{46}$
In this study, dyslipidemia was significantly associated with fasting blood glucose. The study participants with higher blood glucose values were 2 times more likely to develop dyslipidemia than normal glucose values. A similar observation was reported from Ethiopia, ${ }^{28}$ and Kenya. $^{29}$

\section{Conclusion}

In this study, a high (58\%) burden of lipid profile abnormalities was observed in patients with metabolic syndrome, and increasing age, higher BMI, central obesity, hypertension, and high blood glucose level were independent predictors of dyslipidemia. The findings of this study should be considered for the prevention and control of dyslipidemia and its predictors among patients with metabolic syndrome.

\section{Limitation of the Study}

Our study results should be interpreted under consideration of the following limitation; liver enzymes, insulin resistance, and $\mathrm{Hgb} \mathrm{A} 1 \mathrm{C}$ levels were not assessed due to logistic constraint, and causality link between dyslipidemia and independent predictors is not inferred due to the cross-section nature of the study. We did not include nonmetabolic syndrome subjects with and without dyslipidemia as a comparison group which may provide additional insight.

\section{Data Sharing Statements}

The original data for this study are available from the corresponding author on a reasonable request.

\section{Ethical Consideration}

Ethical clearance was obtained from the Jimma University Institutional Review Board (IRB)/committee. It was sought while we were students in Jimma University. A letter of cooperation was written to JUMC administrative offices. Written informed consent was obtained from each study participant after explaining the purpose and procedures of the study before enrolling in the study and those willing to participate were included. The entire study groups were informed that their response will be kept confidential. All necessary results of the participant were communicated with the physician for proper management. This study was conducted in accordance with the Declaration of Helsinki. 


\section{Acknowledgments}

We would like to acknowledge our study participants for their willingness to give all relevant information. We are grateful to the hospital staff and data collectors for their support during the data collection.

\section{Author Contributions}

All authors made substantial contributions to conception and design, acquisition of data, or analysis and interpretation of data; took part in drafting the article or revising it critically for important intellectual content; agreed to submit to the current journal; gave final approval of the version to be published; and agreed to be accountable for all aspects of the work.

\section{Funding}

No funding was received for this study.

\section{Disclosure}

The authors declared that they have no conflicts of interest for this work.

\section{References}

1. Saklayen MG. The global epidemic of the metabolic syndrome. Curr Hypertens Rep. 2018;20(12):1-8. doi:10.1007/s11906-018-0812-z

2. Jahangiry L, Khosravi-far L, Sarbakhsh P, Kousha A, Entezar Mahdi R, Ponnet K. Prevalence of metabolic syndrome and its determinants among Iranian adults: evidence of IraPEN survey on a bi-ethnic population. Sci Rep. 2019;9(1):1-7. doi:10.1038/s41598019-44486-8

3. Sergio LF, Sandra S. Metabolic syndrome and associated factors in adults of the Amazon region. PLoS One. 2016;11(12):1-14.

4. Osei-Yeboah J, Owiredu WKBA, Norgbe GK, et al. The prevalence of metabolic syndrome and its components among people with type 2 diabetes in the Ho municipality, Ghana: a Cross-Sectional Study. Int J Chronic Dis. 2017;2017:8765804. doi:10.1155/2017/8765804

5. Elizabeth H, Herningtyas TSN. Prevalence and distribution of metabolic syndrome and its components among provinces and ethnic groups in Indonesia. BMC Public Health. 2019;19:1-12.

6. Samrawit SWM. Disease burden and associated risk factors for metabolic syndrome among adults in Ethiopia. BMC Cardiovasc Disord. 2019;19(236):1-8.

7. Tran A, Gelaye B, Girma B, et al. Prevalence of metabolic syndrome among working adults in Ethiopia. Int $J$ Hypertens. 2011;2011:193719. doi:10.4061/2011/193719

8. Gebremeskel GG, Berhe KK, Belay DS, Kidanu BH. The magnitude of metabolic syndrome and its associated factors among patients with type 2 diabetes mellitus in Ayder Comprehensive Specialized Hospital, Tigray, Ethiopia: a Cross-Sectional Study. BMC Res Notes. 2019;12(603):1-7. doi:10.1186/s13104-019-4609-1

9. Halpern A, Mancini MC, Magalhães MEC, et al. Metabolic syndrome, dyslipidemia, hypertension and type 2 diabetes in youth: from diagnosis to treatment. Diabetol Metab Syndr. 2010;2 (55):1-20. doi:10.1186/1758-5996-2-55

10. Rochlani Y, Pothineni NV, Kovelamudi S, Mehta JL. Metabolic syndrome: pathophysiology, management, and modulation by natural compounds. Ther Adv Cardiovasc Dis. 2017;11(8):215-225. doi: $10.1177 / 1753944717711379$
11. Mccracken E, Monaghan M, Sreenivasan S. Pathophysiology of the metabolic syndrome. Clin Dermatol. 2018;36(1):14-20. doi:10.1016/ j.clindermatol.2017.09.004

12. Lee M, Han K, Kim MK, Koh ES, Kim ES. Changes in metabolic syndrome and its components and the risk of type 2 diabetes: a Nationwide Cohort Study. Sci Rep. 2020;10:1-8.

13. Henry N, Ginsberg PRM. The obesity, metabolic syndrome, and type 2 diabetes mellitus pandemic: part I. Increased cardiovascular disease risk and the importance of atherogenic dyslipidemia in persons with the metabolic syndrome and type 2 diabetes mellitus. J Cardiometab Syndr. 2010;4(2):113-119.

14. Anwar A, Devi G, Hospita C, Hanif A. metabolic syndrome; frequency in patients presented with ischemic heart disease. Prof Med $J$. 2018;25(2):277-281.

15. Mani P, Ren H, Neeland IJ, et al. The association between HDL particle concentration and incident metabolic syndrome in the Multi-Ethnic Dallas Heart Study. Diabetes Metab Syndr. 2018;11 (1):1-13.

16. Devi SA, Jyothi B. Dyslipidemia in metabolic syndrome: an overview of lipoprotein- related disorders. Int $J$ Cardiol Lipidol Res. 2017;4(1):6-15. doi:10.15379/2410-2822.2017.04.01.02

17. Natah TM, Mohammed AK. Lipid abnormalities in metabolic syndrome patients. Adv Nat Appl Sci. 2014;8(13):25-29.

18. Alipour N, Wong ND, Malik S. The metabolic syndrome and dyslipidemia in primary and secondary prevention: examining the implications of recent trials The metabolic syndrome and dyslipidemia in primary and secondary prevention: examining the implications of recent trials. Clin Lipidol. 2012;7(2):223-239. doi:10.2217/ clp. 12.13

19. Nolan PB, Carrick-Ranson G, Stinear JW, Reading SA, Dalleck LC. Prevalence of metabolic syndrome and metabolic syndrome components in young adults: a pooled analysis. Prev Med Rep. 2017;7:211-215. doi:10.1016/j.pmedr.2017.07.004

20. Blaton VH, Korita I, Bulo A. How is a metabolic syndrome related to dyslipidemia? Biochem Med. 2008;18(1):14-24. doi:10.11613/ BM.2008.003

21. Kolovou G, Cardiac O, Anagnostopoulou KK. Pathophysiology of dyslipidemia in the metabolic syndrome. Postgrad Med J. 2005;81 (956):358-366. doi:10.1136/pgmj.2004.025601

22. Ruotolo G, Howard BV. Dyslipidemia of the metabolic syndrome. Cardiol Rep. 2002;4(6):494-500. doi:10.1007/s11886-002-0113-6

23. National Cholesterol Education Program. Third Report of the National Cholesterol Education Program (NCEP) Expert Panel on Detection, Evaluation, and Treatment of High Blood Cholesterol in Adults (Adult Treatment Panel III). 2001.

24. World health organization. International Guide for Monitoring Alcohol Consumption. 2000.

25. Caspersen CJ, Christenson GM. Physical activity, exercise, and physical fitness: definitions and distinctions for health-related research. Public Health Rep. 1985;100(2):126.

26. Fiorentino M, Landais E, Bastard G, Carriquiry A, Wieringa FT, Berger J. Urban school children, and adolescents: results from two $24 \mathrm{~h}$ recalls in state primary schools in Dakar. Nutrients. 2016;8 (10):1-17. doi:10.3390/nu8100650

27. Shiferaw B, Tagesech Y, Mohammed AE. Dyslipidemia and associated factors among diabetic patients attending Durame General Hospital in Southern Nations, Nationalities, and People's Region. Diabetes Metab Syndr Obes Targets Ther. 2017;10:265-271. doi:10.2147/DMSO.S135064

28. Solomon T, Alemseged F. Risk factors for cardiovascular diseases among diabetic patients in southwest Ethiopia. Ethiop J Health Sci. 2010;20(2):122-128.

29. Victor S, Lydia K, Jemimah K, Drusilla M. Prevalence of dyslipidemia and the associated factors among type 2 diabetes patients in Turbo Sub- County, Kenya. J Endocrinol Diabetes. 2017;4(5):1-9. doi:10.15226/2374-6890/4/5/00190 
30. Bello-ovosi BO, Ovosi JO, Ogunsina MA, Asuke S, Ibrahim MS. Prevalence and pattern of dyslipidemia in patients with type 2 diabetes mellitus in Zaria, Northwestern Nigeria. Pan Afr Med J. 2019;34(123):1-9. doi:10.11604/ pamj.2019.34.123.18717

31. Mohammadbeigi A, Farahani H, Moshiri E, Sajadi M, Ahmadli R. Prevalence of metabolic syndrome and associations with lipid profiles in Iranian men: a population-based screening program. World J Mens Health. 2018;36(1):50-56. doi:10.5534/wjmh.17014

32. Yang Z, Ding X, Liu J, Duan P, Si L, Binghua Wan PT. Associations between anthropometric parameters and lipid profiles in Chinese individuals with age $>40$ years and BMI $<28 \mathrm{~kg} / \mathrm{m}$ 2. PLoS One. 2017;12(6):1-11.

33. Singh O, Gupta M, Khajuria V. lipid profile and its relationship with blood glucose levels in. Natl J Physiol Pharm Pharmacol. 2015;5 (2):134-137. doi:10.5455/njppp.2015.5.051120141

34. Cláudia MS, Claudileide SS, Edvânia CA, Ilma Kruze GA, Alcides D. Lipid and glucose profiles in outpatients and their correlation with anthropometric indices. Port J Cardiol. 2013;32(1):35-41.

35. Nazaimoon W, Mohamud W, Ismail A, Sharifuddin A. Prevalence of metabolic syndrome and its risk factors in adult Malaysians: results of a nationwide survey. Diabetes Res Clin Pract. 2012;96(1):91-97. doi:10.1016/j.diabres.2011.11.020

36. Wong-Mcclure RA, Gregg EW, Barceló A, et al. Prevalence of metabolic syndrome in Central America: a Cross-Sectional Population-Based Study. Rev Panam Salud Publ. 2015;38 (3):202-208.

37. Belete B, Biadgo B, Melak T, et al. The prevalence of metabolic syndrome and its components among type 2 diabetes mellitus patients at a Tertiary Hospital, Northwest Ethiopia. Ethiop J Health Sci. 2018;28(5):645-654.

38. Tadewos A, Ambachew H, Assegu D. Pattern of metabolic syndrome in relation to gender among type-II DM patients in Hawassa University Comprehensive Specialized Hospital, Hawassa, Southern Ethiopia. Health Sci J. 2017;11(3):1-8.
39. Camilla Ribeiro LF, Carla Campos MM, Ivelisse Fhrideraid Alves FC, Mônica Oliveira C, Simões MODS, Carvalho DFD. Persistent metabolic syndrome and risk of cardiovascular disease in children and adolescents. Rev Bras Enferm. 2018;71(3):1013-1021. doi:10.1590/0034-7167-2016-0564

40. Sison O, Castillo-Carandang N, Ladia MA, et al. Prevalence of metabolic syndrome and cardiovascular risk factors among community health workers in selected villages in the Philippines. $J A S E A N$ Fed Endocr Soc. 2019;34(2):171-179.

41. Dhoj TS, Raj KCS, Santosh G, Deepika G. Dyslipidemia in type 2 diabetes mellitus. J Pathol Nepal. 2017;7:1149-1154. doi:10.3126/ jpn.v7i2.17978

42. Gebreyes YF, Goshu DY, Geletew TK, et al. Prevalence of high blood pressure, hyperglycemia, dyslipidemia, metabolic syndrome and their determinants in Ethiopia: evidence from the national NCDs STEPS. PLoS One. 2018;13(5):1-18. doi:10.1371/journal. pone.0194819

43. Qi L, Ding X, Tang W, Li Q, Mao D, Wang Y. Prevalence and risk factors associated with dyslipidemia in Chongqing, China. Int $J$ Environ Res Public Health. 2015;60(10):13455-13465. doi:10.3390/ijerph121013455

44. Bekele GE, Thupayagale-tshweneagae G. Prevalence and associated factors of metabolic syndrome and its individual components among adolescents. Int J Public Health Sci. 2020;9(1):46-56.

45. Wube TB, Begashaw TA, Hirigo AT. Prevalence of dyslipidemia and its correlation with anthropometric and blood pressure variables among type-2 diabetic patients. J Diabetes Endocrinol. 2020;11 (1):10-17. doi:10.5897/JDE2019.0132

46. Pokharel DR, Khadka D, Sigdel M, et al. Prevalence and pattern of dyslipidemia in Nepalese individuals with type 2 diabetes. BMC Res Notes. 2017;10(1):1-11. doi:10.1186/s13104-017-2465-4

47. Narindrarangkura P, Bosl W, Rangsin R, Hatthachote P. Prevalence of dyslipidemia associated with complications in diabetic patients: a nationwide study in Thailand. BMC Lipids Health Dis. 2019;3:1-8.
Vascular Health and Risk Management

\section{Publish your work in this journal}

Vascular Health and Risk Management is an international, peerreviewed journal of therapeutics and risk management, focusing on concise rapid reporting of clinical studies on the processes involved in the maintenance of vascular health; the monitoring, prevention and treatment of vascular disease and its sequelae; and the involvemen of metabolic disorders, particularly diabetes. This journal is indexed on PubMed Central and MedLine. The manuscript management system is completely online and includes a very quick and fair peerreview system, which is all easy to use. Visit http://www.dovepress. com/testimonials.php to read real quotes from published authors. 